\title{
Scheduling Construction Projects Under Fuzzy Modelling of Resource Constraints
}

\author{
Janusz Kulejewski ${ }^{1}$, Nabi Ibadov $^{1 *}$, and Michał Krzemiński ${ }^{1}$ \\ ${ }^{1}$ Warsaw University of Technology, Faculty of Civil Engineering, Institute of Building Engineering, \\ Division of Production Engineering and Construction Management, ul. Lecha Kaczyńskiego 16, 00- \\ 637 Warsaw, Poland
}

\begin{abstract}
Paper presents the original method of construction scheduling using fuzzy sets theory. The essence of the method is to obtain an optimal construction schedule based on the solution of the fuzzy RCPS problem with flexible restrictions. The article introduces two important modifications of the considered issue. These modifications are: maximization of the degree of fulfillment of customer preferences regarding the time span of the project implementation and the contractor's preference regarding the level of use of renewable resources, for example the level of employment of workers. The article also contains a numerical example showing the procedure for applying the described method.
\end{abstract}

\section{Introduction}

A distinctive feature of construction projects is the uniqueness of conditions for their implementation. This uniqueness should be understood as the implementation of an object with unique operational and technical parameters, in a unique environment (participants of the undertaking, market conditions, conditions at the construction site, etc.). The uniqueness of the object and the conditions of its implementation implies the uncertainty of planning data, on the basis of which the time of the undertaking is assessed for the purpose of making a decision on its acceptance for implementation or rejection. Such decisions are made both by the investor - the owner of the undertaking, as well as the contractor, considering the advisability of participating in the implementation of the undertaking.

Traditionally, this uniqueness is understood as the uncertainty of the project environment and handled by stochastic approaches: probabilistic-based PERT method or simulation methods. This kind of uncertainty, associated with randomness, is modeled by the distributions of probability of activity durations [7]. Reality uncertainty of the conditions for the construction of a building does not have a stochastic character. Therefore, the durations data of the works are often formulated imprecisely[5], [6]. The theory of fuzzy sets developed by Zadeh can be used to process imprecise data [15]. The use of fuzzy set theory for the analysis of the network model was presented, among others, by Prade [13], Chanas and Kamburowski [1], McCahon and Lee [11], Rommelfanger [14]. In turn, the application of fuzzy set theory to solve scheduling problems with limited availability of

\footnotetext{
* Corresponding author: n.ibadov@il.pw.edu.pl
} 
resources was presented, among others, by Lorterapong [10], Hapke and Słowiński [3], Hapke et. al. [4] Knyazeva et al. [8]. Pan and the others [12] have shown that these problems are solved by fuzzy priority heuristics and computational metaheuristic algorithms.

In this article, the authors discussed the problem of fuzzy schedule optimization with limited resources (resource-constrained project scheduling - RCPS), however, taking into account two important modifications of the considered issue. Namely, the maximization of the degree of fulfillment of customer preferences regarding the time span of the project implementation and the preference of the contractor regarding the level of use of renewable resources, for example - the employment level of workers. Fulfilling the preferences of the contractor in this respect is therefore a prerequisite for optimizing the schedule.

\section{Methodological approach to the problem under consideration}

In order to solve the issue raised, several theoretical foundations are presented. Assume that the possible duration of an activity is modeled by a trapezoidal or triangular fuzzy number $T_{j}$. The fuzzy schedule is a collection of regular schedules, obtained for the various possible outcomes of durations of individual works. In preparing each such regular schedule, first

we determine an $\alpha$-cross of a fuzzy number $T_{j}$ at a level $\alpha_{j} \in[0,1]$.

Any real number $t_{j}^{\alpha_{j}, \gamma_{j}}$ from the interval $T_{j}^{\alpha_{j}}=\left[T_{j_{\mathrm{L}}}^{\alpha_{j}}, T_{j_{\mathrm{U}}}^{\alpha_{j}}\right]$ is selected as follows:

$$
t_{j}^{\alpha_{j}, \gamma_{j}}=\gamma_{j} T_{j_{\mathrm{L}}}^{\alpha_{j}}+\left(1-\gamma_{j}\right) T_{j_{\mathrm{U}}}^{\alpha_{j}}
$$

where $\gamma_{j} \in[0,1]$ is a coefficient of optimism, characterizing the contractors attitude to the risk of the underestimation an unknown (yet) duration of an activity $j$.

I was also assumed that, $T_{c}=\left(t_{c 1}, t_{c 2}, t_{c 3}, t_{c 4}\right)$ will be a trapezoidal number, modeling the time of completion of the construction estimated by the contractor, and $T_{p}=\left(t_{d t}, t_{d t}, t_{d l}\right)$ will be a triangular number, modeling the project makespan according to the client preferences.

Taking into account the assumptions of the theory of possibilities [15], $\alpha$ - crosssections of fuzzy numbers $T_{c}$ and $T_{p}$ with the Hurwicz criterion, the following measure of the degree of fulfillment of the preferences of the ordering party is obtained [7]:

$$
\operatorname{Deg}\left(T_{\mathrm{c}} \leq T_{p}\right)=\beta_{\mathrm{t}} \Pi\left(T_{\mathrm{c}} \leq T_{p}\right)+\left(1-\beta_{\mathrm{t}}\right) \mathrm{N}\left(T_{\mathrm{c}} \leq T_{p}\right)
$$

where $\beta_{t} \in[0,1]$ is a factor that characterizes the contractor's attitude to the risk of not fulfilling the client's preferences as to the time span of project implementation, $\Pi\left(T_{\mathrm{c}} \leq T_{p}\right)$ is the measure of possibility, $N\left(T_{\mathrm{c}} \leq T_{p}\right)$ is the measure of necessity.

Figure 1 shows the comparison of the numbers $T_{c}$ i $T_{p}$. 


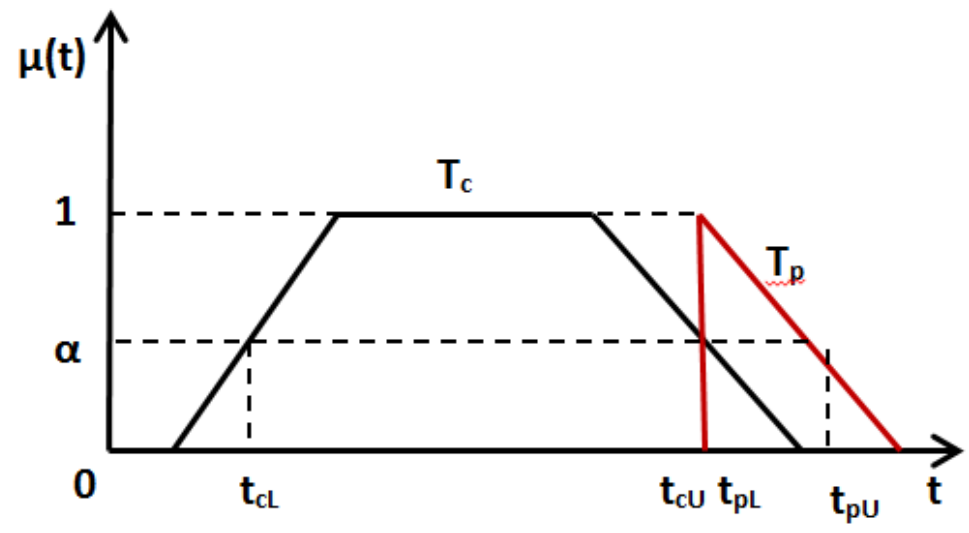

Fig. 1. Comparison of a fuzzy estimation of the project implementation time with the time preferred by the client.

Let $R_{k}=\left(r_{k 1}, r_{k 1}, r_{k 2}\right)$ be a fuzzy triangle number, modeling the preferred use of the $k$ - th renewable resource. The assessment of the satisfaction of the contractor's preferences amounts to assessing the fulfillment of the relationship $r_{k} \leq R_{k}$, Fig.2.

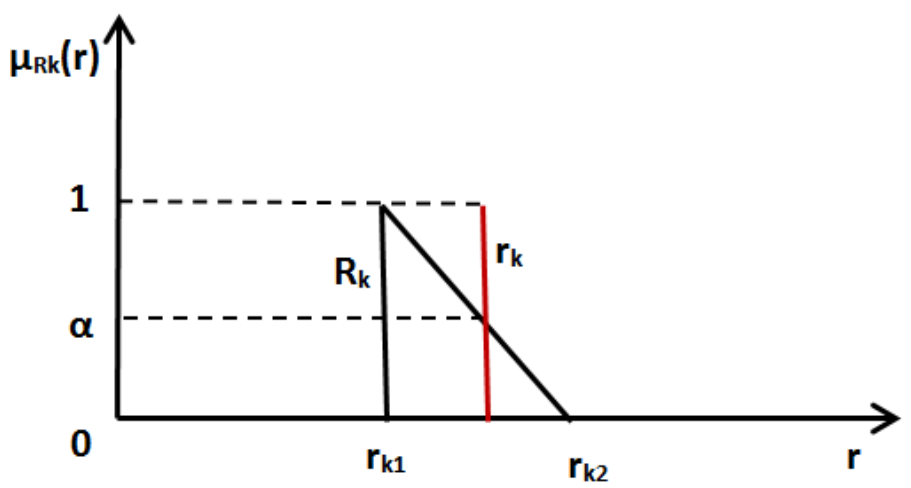

Fig. 2. Assessment of the fulfillment degree of the contractor's preferences.

Based on the assumptions of the theory of possibilities with using the Hurwicz criterion, the following measure of the degree of fulfillment of preferences of the contractor is obtained:

$$
\operatorname{Deg}\left(r_{k} \leq R_{k}\right)=\beta_{r} \Pi\left(r_{k} \leq R_{k}\right)+\left(1-\beta_{r}\right) N\left(r_{k} \leq R_{k}\right)
$$

where:

$\beta_{t} \in[0,1]-$ coefficient characterizing the contractor's attitude to the risk of not meeting preferences as to the level of consumption of renewable resources,

Let's present solutions of the subject under the procedures of the article presented in the article [7] on the basis of a numerical example. 


\section{Numerical example}

An example of a construction project is being considered, as in Fig. 3.

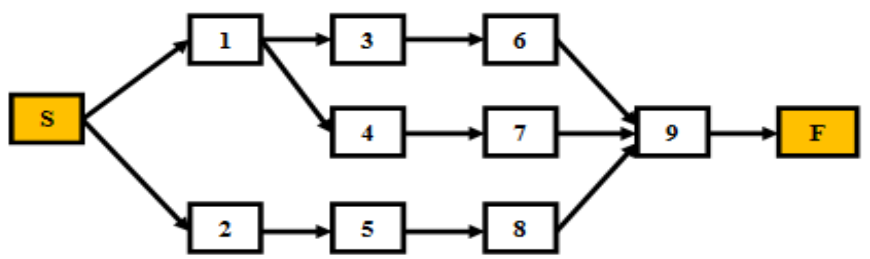

Fig. 3. A network model of an example of a construction project.

Execution time of work and number of employed workers are given in Table 1.

The following planning restrictions have been assumed:

- The client's preferences regarding the limitation of the time span allocated for the execution of works are modeled by a triangular fuzzy number $T_{p}=(45,45,60)$.

- The limit on the employment of daily workers according to the preference of the contractor models the triangular fuzzy number $R=(18,18,24)$.

- The minimum required by the contractor degree of fulfillment of preferences regarding the daily employment level of workers is $\operatorname{Deg}_{\min }(r \leq R)=0,30$.

- The contractor is characterized by a neutral attitude to risk: $\beta=0,50$.

The problem can be presented as follows:

1. Goal function:

$$
\operatorname{Max} F: F=\operatorname{Deg}\left(T_{c} \leq T_{p}\right)
$$

2. Restrictive conditions:

$$
\begin{aligned}
& S_{j} \geq S_{i} \oplus T_{i} ; j \in\{\operatorname{Succ}(i)\} ; S_{i} \geq 0 ; T_{i} \geq 0 \\
& \operatorname{Deg}\left(r_{k} \leq R_{k}\right) \geq \operatorname{Deg}_{\min }\left(r_{k} \leq R_{k}\right),{\widehat{\alpha_{j} \in[0 ; 1]}}_{\gamma_{\mathrm{j}} \in[0 ; 1]}^{\wedge}
\end{aligned}
$$

where $S_{i}, S_{j}$ are fuzzy start times of activities $i$ and $j, T_{i}$ is a fuzzy duration of $i$ activity .

$R_{k}=\left(r_{k 1}, r_{k 1}, r_{k 2}\right)$ is a triangular fuzzy number, modeling the consumption of a $\left(r_{k}\right)-k-t h$ resource according to the contractors preferences.

Table 1. Fuzzy times of completion of works and number of employed workers.

\begin{tabular}{|c|c|c|}
\hline $\begin{array}{c}\text { Activity, } \\
\boldsymbol{j}\end{array}$ & Fuzzy duration $\boldsymbol{T}_{\boldsymbol{j}}$ & $\begin{array}{c}\text { The number of } \\
\text { workers } \boldsymbol{r}_{\boldsymbol{j}}\end{array}$ \\
\hline START & $(0,0,0,0)$ & - \\
\hline $\mathbf{1}$ & $(4,5,5,6)$ & 17 \\
\hline $\mathbf{2}$ & $(3,4,4,5)$ & 12 \\
\hline $\mathbf{3}$ & $(3,4,4,5)$ & 8 \\
\hline $\mathbf{4}$ & $(2,3,3,4)$ & 10 \\
\hline $\mathbf{5}$ & $(7,8,8,9)$ & 11 \\
\hline $\mathbf{6}$ & $(8,9,9,10)$ & 9 \\
\hline $\mathbf{7}$ & $(6,7,7,8)$ & 11 \\
\hline $\mathbf{8}$ & $(3,4,4,5)$ & 6 \\
\hline $\mathbf{9}$ & $(8,9,9,10)$ & 9 \\
\hline FINISH & $(0,0,0,0)$ & - \\
\hline
\end{tabular}


The prepared schedule should ensure maximum fulfillment of the client's preferences regarding the time span of the works and taking into account the contractor's preferences regarding the daily employment level of workers.

How to solve an exemplary task was described below.

\section{1) Selection of the priority rule.}

The $\min S L K$ rule was chosen, granting priority to access resources to activities with a lower, total supply of time.

\section{2) Analysis of the initial network model with fuzzy work times.}

Let the times of performing activities be expressed by trapezoidal fuzzy numbers $T_{i}$. Analyzing fuzzy network $S$,forward”, fuzzy terms of the earliest start and the earliest finish of the $j$-th activities are determined.

$$
E S_{j}=\max _{i \in \operatorname{Pred}\{(j)\}}\left\{E S_{i} \oplus T_{i}\right\} ; E F_{j}=E S_{j} \oplus T_{j} ; j=1, \ldots, J
$$

The fuzzy project completion date is described as:

$$
T_{c}=E F J
$$

where $T_{c}$ is modeled using the ordered four $\left(t_{c 1}, t_{c 2}, t_{c 3}, t_{c 4}\right)$,

$t_{c 1} \leq t_{c 2} \leq t_{c 3} \leq t_{c 4}$.

Similarly, fuzzy dates for the earliest start and the earliest finish of the $i$-th (preceding) activity can be described.

To determine the latest finish of activity $i$ :

$$
L F_{i}=\left\{\begin{array}{c}
\min _{j \in \operatorname{Succ}(i)}\left\{L F_{j} \oplus\left(-D_{i}\right\}, \quad \operatorname{Succ}(i) \neq \varnothing\right. \\
T, \quad \operatorname{Succ}(i)=\varnothing
\end{array}\right.
$$

where:

$\tilde{L F_{i}}$ - fuzzy date of the latest start of activity $i$

$\{\operatorname{Succ}(i)\}-$ set of work successors $i$;

$\tilde{L F_{j}}{ }_{\text {- fuzzy date of the latest finish of activity } j ;}$

$\tilde{D}_{j}$ - fuzzy activity time $j$

$T$ - fuzzy project completion date, determined using the dependence (8);

to determine the latest start of activity $i$ :

$$
\tilde{L S} \tilde{S}_{i} \tilde{L F}_{i} \oplus\left(-\tilde{D}_{i}\right)
$$

to determine the fuzzy total slack of time for $i$ : 


$$
\tilde{T F_{i}}=\tilde{L F_{i}} \oplus\left(-\tilde{E F_{i}}\right)
$$

In order to rank the activities due to the increasing value of the total supply of time with min $S L K$ rule, well known methods of comparing fuzzy numbers of $T F_{i}$ are used, for example - using the centroid method introduced by Cheng [2].

Table 2 presents the results of the analysis.

Table 2. Integration of network model analysis results.

\begin{tabular}{|c|c|c|c|c|c|c|}
\hline $\begin{array}{c}\text { Activity, } \\
j\end{array}$ & $\begin{array}{c}\text { Fuzzy } \\
\text { duration } T_{j}\end{array}$ & $\begin{array}{l}\text { Fuzzy early } \\
\text { start } \boldsymbol{E} \boldsymbol{S}_{\boldsymbol{j}}\end{array}$ & $\begin{array}{c}\text { Fuzzy early } \\
\text { finish } \boldsymbol{E} \boldsymbol{F}_{\boldsymbol{j}}\end{array}$ & $\begin{array}{c}\text { Fuzzy } \\
\text { latest start } \\
L S_{j}\end{array}$ & $\begin{array}{l}\text { Fuzzy latest } \\
\text { finish } L F_{j}\end{array}$ & $\begin{array}{c}\text { Fuzzy } \\
\text { total float } \\
\text { TF }_{j}\end{array}$ \\
\hline START & $(0,0,0,0)$ & $(0,0,0,0)$ & $(0,0,0,0)$ & $(0,0,0,0)$ & $(0,0,0,0)$ & $\begin{array}{c}(0,0,0 \\
0)\end{array}$ \\
\hline 1 & $(4,5,5,6)$ & $(0,0,0,0)$ & $(4,5,5,6)$ & $(0,0,0,0)$ & $(4,5,5,6)$ & $\begin{array}{c}(0,0,0 \\
0)\end{array}$ \\
\hline 2 & $(3,4,4,5)$ & $(0,0,0,0)$ & $(3,4,4,5)$ & $(2,2,2,2)$ & $(5,6,6,7)$ & $\begin{array}{c}(2,2,2, \\
2)\end{array}$ \\
\hline 3 & $(3,4,4,5)$ & $(4,5,5,6)$ & $(7,9,9,11)$ & $(4,5,5,6)$ & $(7,9,9,11)$ & $\begin{array}{c}(-2,0,0, \\
2)\end{array}$ \\
\hline 4 & $(2,3,3,4)$ & $(4,5,5,6)$ & $(6,8,8,10)$ & $(7,8,8,9)$ & $\begin{array}{c}(9,11,11 \\
13)\end{array}$ & $\begin{array}{c}(1,3,3 \\
5)\end{array}$ \\
\hline 5 & $(7,8,8,9)$ & $(3,4,4,5)$ & $\begin{array}{c}(10,12,12, \\
14)\end{array}$ & $(5,6,6,7)$ & $\begin{array}{c}(12,14,14 \\
16)\end{array}$ & $\begin{array}{c}(0,2,2 \\
4)\end{array}$ \\
\hline 6 & $(8,9,9,10)$ & $(7,9,9,11)$ & $\begin{array}{c}(15,18,18 \\
21)\end{array}$ & $(7,9,9,11)$ & $\begin{array}{c}(15,18,18 \\
21)\end{array}$ & $\begin{array}{c}(-4,0,0 \\
4)\end{array}$ \\
\hline 7 & $(6,7,7,8)$ & $(6,8,8,10)$ & $\begin{array}{c}(12,15,15, \\
18)\end{array}$ & $\begin{array}{c}(9,11,11, \\
13)\end{array}$ & $\begin{array}{c}(15,18,18, \\
21)\end{array}$ & $\begin{array}{c}(-1,3,3, \\
7)\end{array}$ \\
\hline 8 & $(3,4,4,5)$ & $\begin{array}{c}(10,12,12, \\
14)\end{array}$ & $\begin{array}{c}(13,16,16 \\
19)\end{array}$ & $\begin{array}{c}(12,14,14, \\
16)\end{array}$ & $\begin{array}{c}(15,18,18 \\
21)\end{array}$ & $\begin{array}{c}(-2,2,2 \\
6)\end{array}$ \\
\hline 9 & $(8,9,9,10)$ & $\begin{array}{c}(15,18,18, \\
21)\end{array}$ & $\begin{array}{c}(23,27,27, \\
31)\end{array}$ & $\begin{array}{c}(15,18,18, \\
21)\end{array}$ & $\begin{array}{c}(23,27,27, \\
31)\end{array}$ & $\begin{array}{c}(-6,0,0, \\
6)\end{array}$ \\
\hline FINISH & $(0,0,0,0)$ & $\begin{array}{c}(23,27,27, \\
31)\end{array}$ & $\begin{array}{c}(23,27,27, \\
31)\end{array}$ & $\begin{array}{c}(23,27,27, \\
31)\end{array}$ & $\begin{array}{c}(23,27,27, \\
31)\end{array}$ & $\begin{array}{c}(-8,0,0, \\
8)\end{array}$ \\
\hline
\end{tabular}

3) Arranging actions in the order resulting from the selected priority rule.

Table 3 shows the distances between the gravity centers of the fuzzy number $T F_{j}$ and the origin of the coordinate system, determined by the Cheng method [2].

Table 3. The distances between the gravity centres of the fuzzy number TFj and the origin of the coordinate system.

\begin{tabular}{|c|c|c|}
\hline $\begin{array}{c}\text { Activity, } \\
\boldsymbol{j}\end{array}$ & $\boldsymbol{T F}_{\boldsymbol{j}}$ & $\boldsymbol{R}\left(\boldsymbol{T F}_{\boldsymbol{j}}\right)$ \\
\hline START & $(0,0,0,0)$ & 0 \\
\hline $\mathbf{1}$ & $(0,0,0,0)$ & 0 \\
\hline $\mathbf{2}$ & $(2,2,2,2)$ & 2 \\
\hline $\mathbf{3}$ & $(-2,0,0,2)$ & 0 \\
\hline $\mathbf{4}$ & $(1,3,3,5)$ & 3 \\
\hline $\mathbf{5}$ & $(0,2,2,4)$ & 2 \\
\hline $\mathbf{6}$ & $(-4,0,0,4)$ & 0 \\
\hline $\mathbf{7}$ & $(-1,3,3,7)$ & 3 \\
\hline $\mathbf{9}$ & $(-2,2,2,6)$ & 2 \\
\hline FINISH & $(-6,0,0,6)$ & 0 \\
\hline
\end{tabular}


The ranking of activities based on the $R(T F j)$ index is as follows:

S - 1 - 3 - 6 - 9 - F - 2 - 5 - 8 - 4 - 7 .

Taking into account technological dependencies between activities in the network model, the following order was adopted:

$\mathrm{S}-1-3-6-2-5-8-4-7-9-\mathrm{F}$.

4) Determining the dependence of additional priorities resulting from the chosen rule.

5. Checking which additional dependencies are sufficient to ensure the required degree of fulfillment of the contractor's preferences as to the maximum level of employment of the workers.

The check consisted in solving the task described by objective function (4) with limiting conditions (5) and (6). A metaheuristic search algorithm with forbidden movements was used for the solution, cooperating with a simulator generating random numerical values of $\alpha_{j}$ i $\gamma_{j}$ parameters.

The solution is presented in Fig. 4.

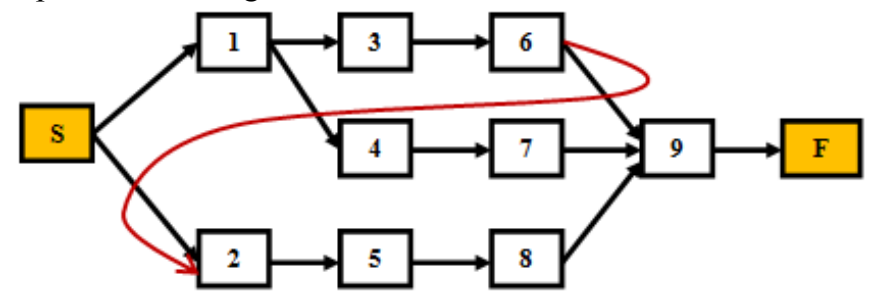

Fig. 4. Solution of the exemplary FRCPS task.

In the solution, the spread time is modeled by the fuzzy number $T_{c}=(36,43,43,50)$.

The degree of fulfillment of customer preferences is $\operatorname{Deg}\left(T_{\mathrm{c}} \leq T_{p}\right)=0.64$.

The degree of fulfillment of the contractor's preferences is $\operatorname{Deg}(r \leq R)=0.44>0.30$.

Table 4 gives the data for an exemplary regular schedule obtained on the basis of the above solution.

Table 4. Data for an exemplary standard schedule.

\begin{tabular}{|c|c|c|c|c|c|c|}
\hline $\begin{array}{c}\text { Activity, } \\
\boldsymbol{j}\end{array}$ & $\begin{array}{c}\boldsymbol{F u z z y} \\
\text { duration } \boldsymbol{T}_{\boldsymbol{j}}\end{array}$ & $\boldsymbol{\alpha}_{\mathbf{j}}$ & $\boldsymbol{\gamma}_{\mathbf{j}}$ & $\boldsymbol{T}_{\boldsymbol{j} \boldsymbol{L}}$ & $\boldsymbol{T}_{\boldsymbol{j} \boldsymbol{U}}$ & $\boldsymbol{t}_{\boldsymbol{j}}$ \\
\hline $\mathbf{1}$ & $(4,5,5,6)$ & 0.56 & 0.25 & 4.56 & 5.44 & 5.22 \\
\hline $\mathbf{2}$ & $(3,4,4,5)$ & 0.76 & 0.01 & 3.76 & 4.24 & 4.24 \\
\hline $\mathbf{3}$ & $(3,4,4,5)$ & 0.20 & 0.07 & 3.20 & 4.80 & 4.69 \\
\hline $\mathbf{4}$ & $(2,3,3,4)$ & 0.05 & 0.71 & 2.05 & 3.95 & 2.60 \\
\hline $\mathbf{5}$ & $(7,8,8,9)$ & 0.08 & 0.35 & 7.08 & 8.92 & 8.28 \\
\hline $\mathbf{6}$ & $(8,9,9,10)$ & 0.46 & 0.24 & 8.46 & 9.54 & 9.28 \\
\hline $\mathbf{7}$ & $(6,7,7,8)$ & 0.23 & 0.04 & 6.23 & 7.77 & 7.71 \\
\hline $\mathbf{8}$ & $(3,4,4,5)$ & 0.06 & 0.06 & 3.60 & 4.40 & 4.35 \\
\hline $\mathbf{9}$ & $(8,9,9,10)$ & 0.06 & 0.41 & 8.60 & 9.40 & 9.07 \\
\hline
\end{tabular}

\section{Conclusions}

The proposed method of fuzzy optimization of the schedule with limited resources (resource-constrained project scheduling - RCPS), introduces a significant modification in the form of maximizing the fulfillment of client preferences regarding the time of project 
implementation and contractor's preferences regarding the level of use of renewable resources, for example - the employment level of workers.

The distinguishing achievement of the proposed method is that it provides optimal solution for the fuzzy RCPS problem with flexible constraints for every possible implementation of work completion times.

On the other hand, ensuring optimal solution for the fuzzy RCPS problem for every possible implementation of operation times is possible thanks to the use of metaheuristic computational algorithms, in combination with a simulation technique.

The presented numerical example of the construction scheduling based on the solution of the fuzzy RCPS optimization problem confirms the correctness of the presented method.

\section{References}

1. S. Chanas, J. Kamburowski, The use of fuzzy variables in PERT. Fuzzy Sets and Systems 5, 11-19 (1981)

2. C.H. Cheng, A new approach for ranking fuzzynumbers by distance method. Fuzzy Sets and Systems 95, 307-317 (1998)

3. M. Hapke, R. Slowinski, Fuzzy priority heuristics for project scheduling. Fuzzy Sets and Systems 83, 291-299 (1996)

4. M. Hapke, A. Jaszkiewicz, R. Slowinski, Interactive analysis of multiple-criteria project scheduling problems. European Journal of Operational Research 107, 315-324 (1998)

5. N. Ibadov, Int. J. Environ. Sci. Technol. (2018). https://doi.org/10.1007/s13762-0181695-x

6. N. Ibadov, Determination of the risk factors impact on the construction projects implementation using fuzzy sets theory. Acta Phys Pol A 130 (1):107-111. https ://doi.org/10.12693 /APhysPolA.130.107

7. N. Ibadov, J. Kulejewski, Evaluation of the Project Timeliness with Fuzzy Constraints, AIP Conf. Proc. 1648, 600002-1-600002-4; doi: 10.1063/1.4912834

8. M. Knyazeva, A. Bozhenyuk, I. Rozenberg, Resource-constrained project scheduling approach under fuzzy conditions. Procedia Computer Science 77, 56 - 64 (2015)

9. D. Kuchta, Miękka matematyka w zarządzaniu. Oficyna Wydawnicza Politechniki Wrocławskiej, Wrocław, (2001)

10. P. Lorterapong, A fuzzy heuristic method for resource-constrained project scheduling. Project Management Journal 25, 12-18 (1994)

11. C.S. McCahon, E.S. Lee, Project network analysis with fuzzy activity times. Computers \& Mathematics with Applications 15, 829-838 (1988).

12. H. Pan, C.-H Yeh, A rule-based approach for fuzzy overhaul scheduling. Lecture Notes in Computer Science (Artificial Intelligence) 3214, 753-763 (2004).

13. H. Prade, Using fuzzy set theory in a scheduling problem: a case study. Fuzzy Sets and Systems 2, 153-165 (1979)

14. H.J. Rommelfanger, Network analysis and informatiom flow in fuzzy environment. Fuzzy Sets and Systems 67, 119-128 (1994)

15. L.A. Zadeh, Fuzzy sets as a basis for a theory of possibility. Fuzzy Sets and Systems 1, 3-28 (1978) 